\title{
Childhood overweight and obesity trends in Canada
}

\section{P. Rao, PhD; E. Kropac, MSc, RN; M. T. Do, PhD; K. C. Roberts, MSc; G. C. Jayaraman, PhD}

This article has been peer reviewed.

\section{Abstract}

Introduction: Excess weight is a key risk factor for chronic disease, and the systematic collection, analysis and reporting of key trends are important to surveillance of overweight and obesity.

Methods: We used univariate analyses to calculate current prevalence estimates of excess weight among Canadian children and youth.

Results: Almost 1 in 7 children and youth is obese. Rates vary based on sociodemographic factors such as age, sex, socioeconomic status and place of residence. Overall, the rates of excess weight have been relatively stable over the past decade.

Conclusion: Ongoing monitoring of childhood obesity will provide useful information to assist with sustained actions to promote healthy weights.

Keywords: overweight, obesity, children, youth, sociodemographic factors

\section{Introduction}

Since obesity is a major risk factor for chronic disease, ${ }^{1}$ it takes a significant toll on the health care system, the economy and the quality of life of Canadians. ${ }^{2}$ Over the last four decades, the prevalence of obesity among children and youth in Canada has increased significantly. ${ }^{3}$ As a result, they are increasingly diagnosed with a range of obesity-related health conditions previously seen almost exclusively among adults, including type 2 diabetes, high cholesterol, high blood pressure, depression, sleep apnea and joint
Tweet this article

\section{Highlights}

- The surveillance of overweight and obesity trends in children and youth is important in informing research, programs and policies.

- The authors analyzed information from several national populationbased surveys, including those with objectively measured data, to provide an update on excess weight in childhood in Canada.

- Almost 1 in 7 children and youth is obese.

- Rates of overweight and obesity vary based on factors such as age, sex, socioeconomic status and place of residence.

problems. ${ }^{1}$ The added concern is that childhood obesity is known to track into adulthood. ${ }^{2}$

We previously reported on trends and projections in obesity among Canadians

FIGURE 1

Prevalence of overweight and obesity, ages 6 to 17 years, Canada, 2004-2012/13

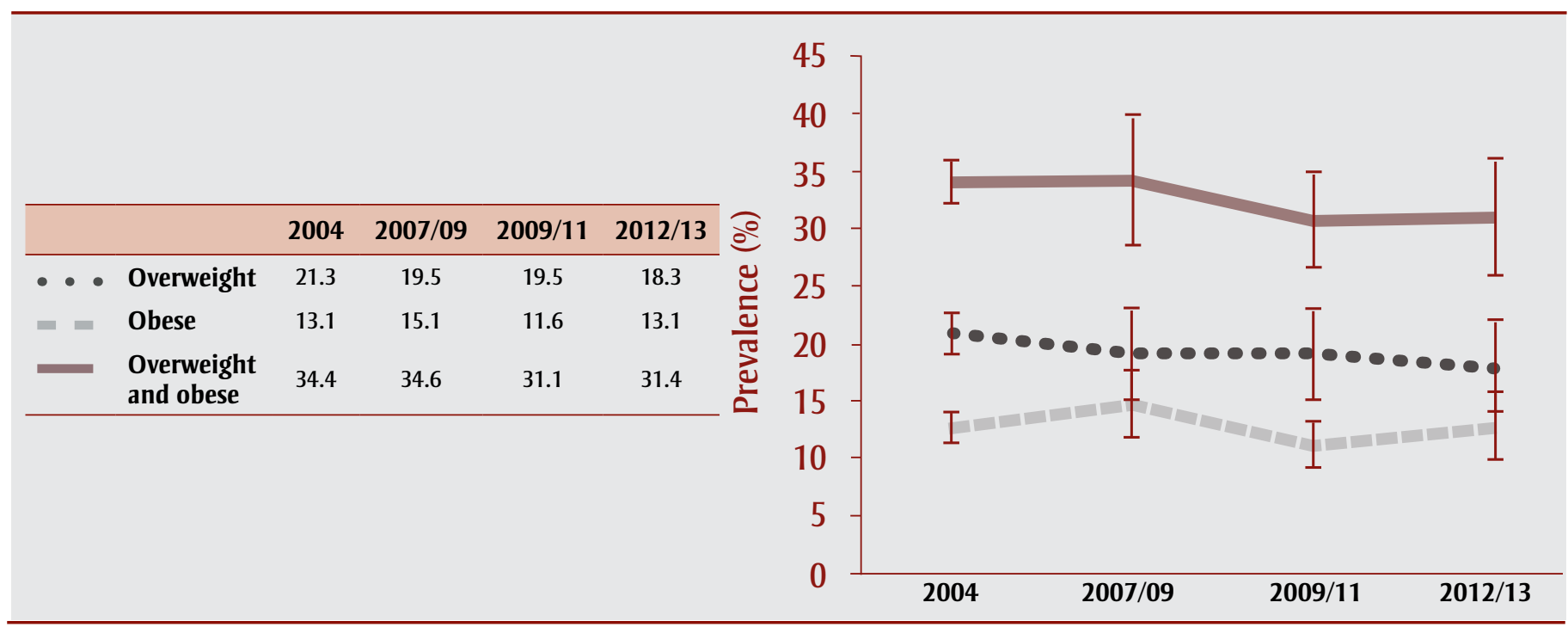

Source: Statistics Canada, Canadian Community Health Survey 2004 and Canadian Health Measures Survey 2007/09, 2009/11, and 2012/13. 
overall. ${ }^{4}$ Regular reporting on childhood obesity as part of the Chronic Disease and Injury Indicator Framework ${ }^{5}$ (CDIIF) provides basic breakdowns of the prevalence of obesity among children and youth by age, sex and sociodemographic factors. In this article, we build on this reporting by providing additional breakdowns using the variables already contained within the CDIIF, which are important to guide research, programs and policy in Canada. Updated trends in childhood overweight (in addition to obesity), trends in both overweight and obesity according to age and sex, an examination of sex differences in the distribution of overweight and obesity by income adequacy (a key sociodemographic factor) and an examination of the distribution of obesity by place of residence elaborate and supplement the surveillance information contained within the CDIIF.

\section{Methods}

\section{Data and data sources}

Body mass index (BMI) is an indirect measure of adiposity (body fat) that correlates with health outcomes, both in the short and the long term. ${ }^{6}$ The Public Health Agency of Canada bases its weight charts on World Health Organization (WHO) growth reference charts: children whose BMI is two standard deviations (SDs) or more above the mean are considered obese and whose BMI is between one and two SDs above the mean are considered overweight. ${ }^{\text {? }}$

The statistics in this paper are based on the results from national population-based surveys. Self-reported measures of height and weight in children have been consistently available for many years, and since

TABLE 1

Sociodemographic determinants of childhood obesity, ages 6 to 17 years, Canada, 2004-2012/13

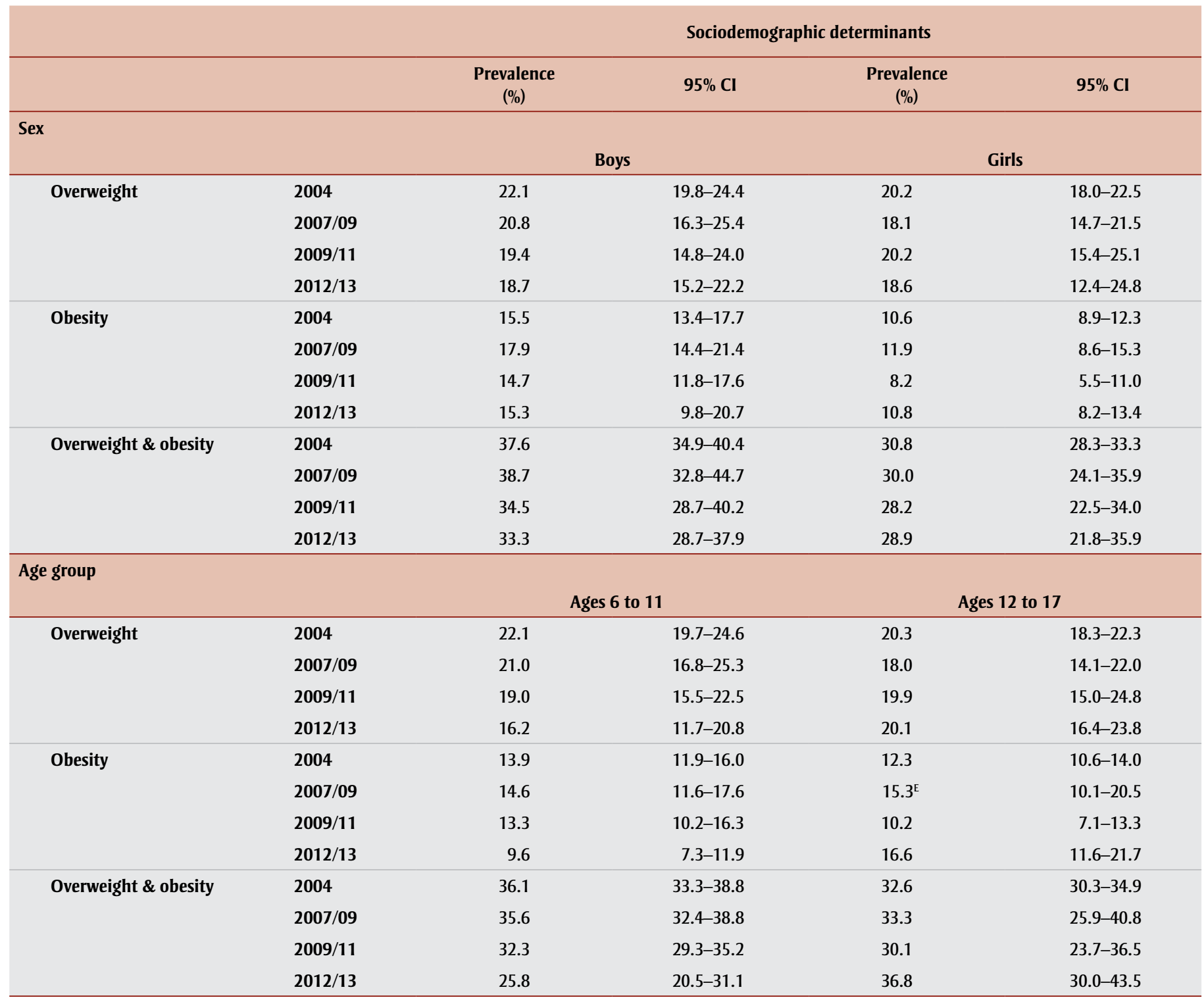

Source: Statistics Canada, Canadian Community Health Survey 2004 and Canadian Health Measures Survey 2007/09, 2009/11, and 2012/13.

Abbreviation: $\mathrm{Cl}$, confidence interval.

${ }^{\mathrm{E}}$ Interpret with caution due to high sampling variability (coefficient of variation between $16.6 \%$ and $33.3 \%$ ). 
FIGURE 2

Prevalence of overweight and obesity by sex, ages 12 to 17 years, Canada, 2004-2014

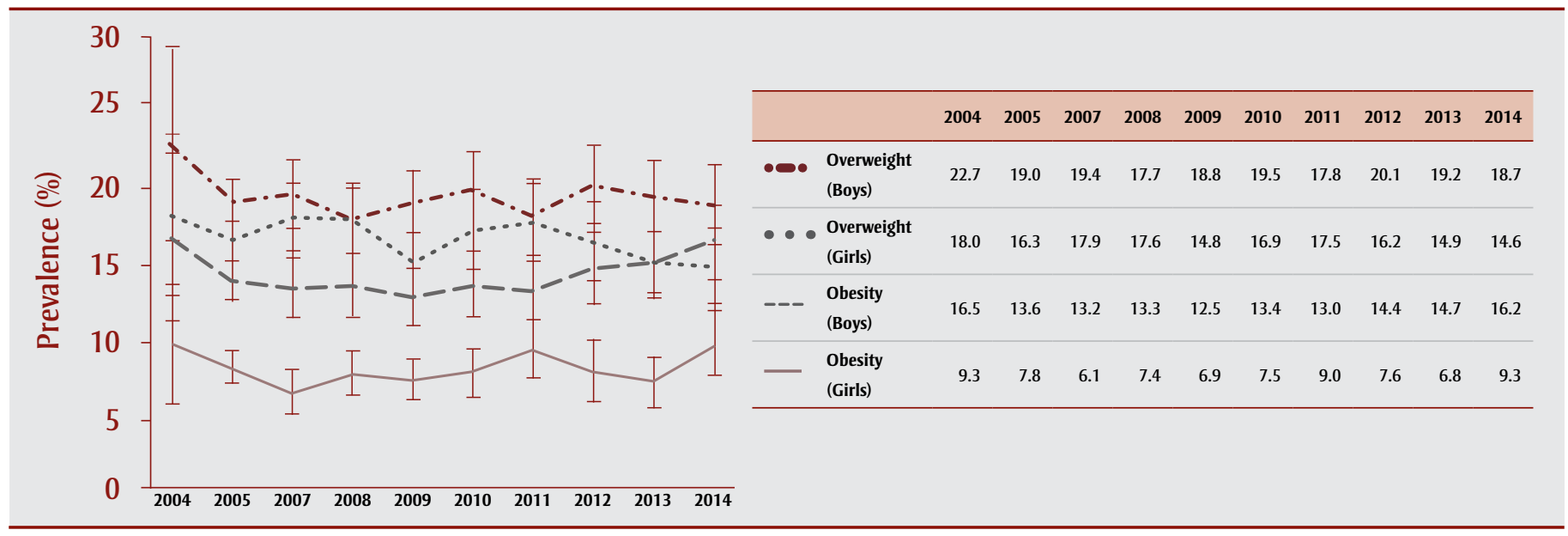

Source: Statistics Canada, Canadian Community Health Survey 2004-2014.

2007, the Canadian Health Measures Survey (CHMS) has routinely collected objectively measured anthropometric data. We used the Canada Health Survey $(1978 / 79)$ to gather objectively measured BMI data for children aged 2 to 17 years; annual cycles of the Canadian Community Health Survey (2004 to 2014) for selfreported BMI data for children and youth aged 12 to 17 years and objectively measured BMI data for children aged 6 to 17 years for 2004; and the Canadian Health Measures Survey (2007/09, 2009/11 and 2012/13) for objectively measured BMI data for children and youth aged 5 to 17 years.

\section{Analyses}

We examined trends and current estimates in childhood obesity using the WHO classification system. To reduce misclassification and bias (based on sex) in self-reported estimates, these data were adjusted using a correction factor that was established based on comparisons of selfreported and objective measures of weight status. $^{8}$ Descriptive analyses were completed using SAS Enterprise Guide version 5.1 (SAS Institute Inc., Cary, NC, USA). Relationships between variables were examined using chi-square tests, with significance at 0.05 , to determine $p$ values. Findings were weighted to reflect the
Canadian household population and 95\% confidence intervals were calculated using bootstrap re-sampling methods. Trends over 10 years are reported, where possible.

\section{Results}

\section{Trends}

In $1978 / 79$, about one in four children (23.3\%; $95 \%$ CI: 20.5-26.0) was overweight or obese. ${ }^{9}$ This proportion is now closer to one in three $(31.4 \%$; $95 \% \mathrm{CI}$ : 26.4-36.4).

FIGURE 3

Prevalence estimates of excess weight by income adequacy level, ages 5 to 17 years, Canada, 2012/13

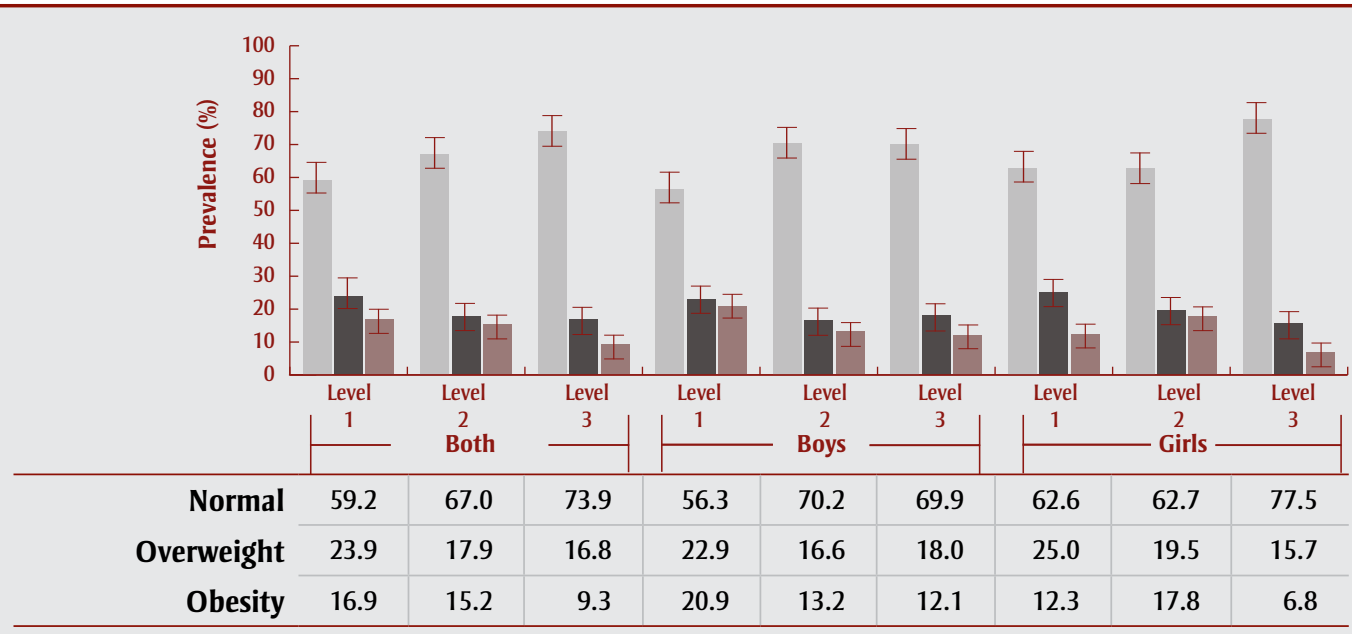

Source: Statistics Canada, Canadian Health Measures Survey 2012/13.

Note: Level 1 is the lowest household income adequacy level while Level 3 is the highest. 
Although objectively measured estimates of excess weight among children and youth have doubled over the past four decades, measures of childhood obesity have remained stable over the last 10 years (Figure 1).

\section{Sex}

Differences in excess weight may arise due to biological reasons, such as sexbased patterning of fat distribution and energy requirements, or societal and cultural gender-based norms, such as food choices and body satisfaction. ${ }^{10}$ Examining objectively measured excess weight over time and comparing these weights between the sexes at each time point does not show any significant difference (Table 1). However, when examining selfreported estimates, the prevalence of obesity among boys is significantly higher than that among girls (Figure 2), and rates of overweight appear to have remained stable.

\section{Age}

As individuals age, changes in activity patterns, hormone levels and muscle mass may all contribute to changes in weight status. In Canada, obesity appears to significantly increase through childhood and adolescence. Based on estimates from $2012 / 13,8.5 \%$ (95\% CI: 6.2-10.9) of 5- to 9-year-olds, $12.9 \%$ (95\% CI: $7.2-18.6$ ) of 10 - to 14 -year-olds and $18.2 \%$ (95\% CI: 12.5-24.0) of 15- to 17-year-olds are obese. In comparison, the $2012 / 13$ rates of overweight are $15.4 \%$ (95\% CI: 11.519.3), $23.0 \%$ (95\% CI: 16.4-29.6) and $17.1 \%$ (95\% CI: 12.5-21.7) for the same age ranges, with age-based differences in excess weight not as apparent for overweight as for obesity. Trends in excess weight over the past decade do not differ significantly between age groups (Table 1).

\section{Socioeconomic status}

Low-income population groups are known to be at increased risk of obesity. ${ }^{11}$ Income adequacy level* was found to be significantly associated $(p=.02)$ with childhood obesity, while having healthier weights was more likely for those with better access to income. Figure 3 shows the prevalence estimates of excess weight by income adequacy level for both sexes and for each sex.

FIGURE 4

Prevalence of overweight and obesity by local health region

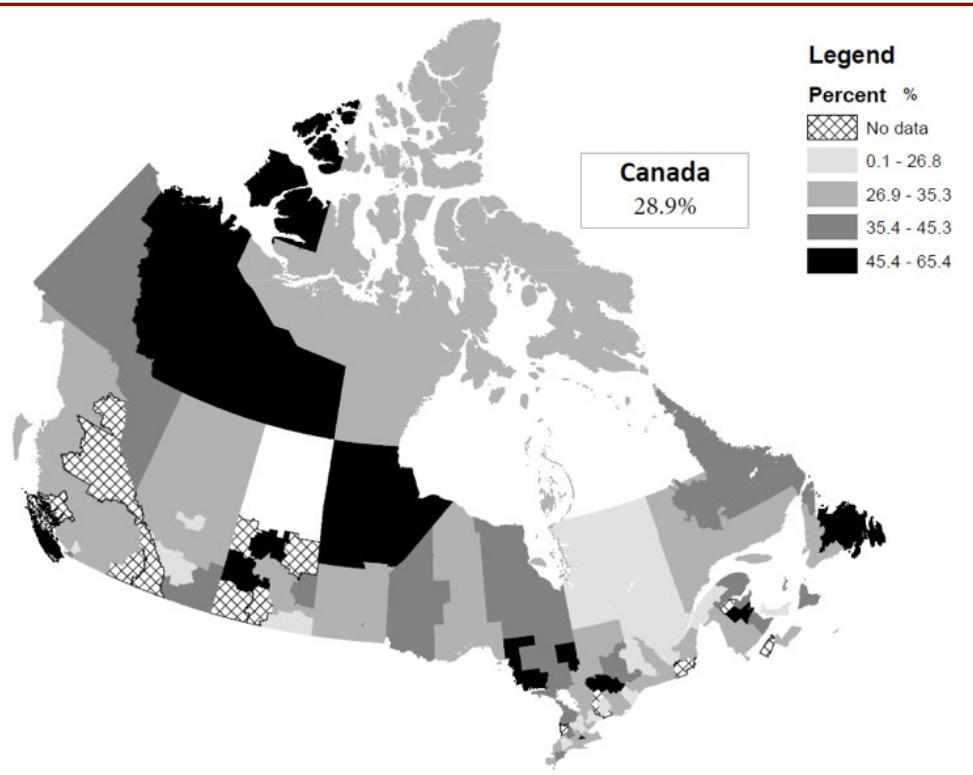

Source: Statistics Canada, Canadian Community Health Survey 2013/14, ages 12 to 17 years.

\section{Place of residence}

While the national average prevalence of excess weight in children and youth is $28.9 \%$ (95\% CI: 27.4-30.4, CCHS 201314), regional differences are observed (Figure 4). International comparisons also demonstrate similar rates: the prevalence of obesity among children is $13.1 \%$ (95\% CI: 10.2-16.1) in Canada (6-17 years), 16.9\% (95\% CI: 14.9-19.2) in the United States (2-19 years, using CDC growth charts ${ }^{12}$ and $20 \%$ in the United Kingdom (2-15 years). ${ }^{13}$

\section{Conclusion}

The stable trends in childhood obesity over the past decade are encouraging. Nevertheless, excess weight remains prevalent. Ongoing monitoring of childhood obesity will provide useful information to assist with sustained actions to promote healthy weights.

\section{References}

1. Public Health Agency of Canada. Actions taken and future directions 2011: curbing childhood obesity: a federal, provincial and territorial framework for action to promote healthy weights. Ottawa (ON): Public Health Agency of Canada; 2011 Nov 25 [cited $2016 \mathrm{Feb}$ 5]. Available from: http://www.phac-aspc.gc.ca/hp-ps /hl-mvs/framework-cadre/2011/hw-os -2011-eng.php
2. Singh AS, Mulder C, Twisk JW, van Mechelen W, Chinapaw MJ. Tracking of childhood overweight into adulthood: a systematic review of the literature. Obes Rev. 2008;9(5):474-88. doi: 10.1111/j.1467 $-789 X .2008 .00475 . x$.

3. Roberts KC, Shields M, deGroh M, Aziz A, Gilbert JA. Overweight and obesity in children and adolescents: results from the 2009 to 2011 Canadian Health Measures Survey. Health Rep. 2012;23(3):37-41.

4. Bancej C, Jayabalasingham B, Wall RW, et al. Evidence brief--trends and projections of obesity among Canadians. Health Promot Chronic Dis Prev Can. 2015;35(7):109-12.

5. Centre for Chronic Disease Prevention, Public Health Agency of Canada. Chronic Disease and Injury Indicator Framework: online data tool, 2015 Edition. Ottawa (ON): Public Health Agency of Canada; 2015. Available from: http://infobase .phac-aspc.gc.ca/cdiif/

6. Janssen I, Katzmarzyk P, Srinivasan S, et al. Utility of childhood BMI in the prediction of adulthood disease: comparison of national and international reference. Obesity Res. 2005;13:1106-15. doi: 10.1038 /oby.2005.129.

\footnotetext{
${ }^{*}$ Household income adequacy is a measure of income that takes into consideration the number of individuals within a household who share the total income, allowing a fair comparison between families, regardless of size.
} 
7. WHO Multicentre Growth Reference Study Group. WHO child growth standards based on length/height, weight and age. Acta Paediatr Suppl. 2006;450:76-85. doi: 10.1111/j.1651-2227.2006.tb02378.x.

8. Connor Gorber S, Shields M, Tremblay MS, McDowell I. The feasibility of establishing correction factors to adjust self-reported estimates of obesity. Health Rep. 2008;19(3):71-82.

9. Shields M, Tremblay MS. Canadian childhood obesity estimates based on WHO, IOTF and CDC cut-points. Int $\mathrm{J}$ Pediatr Obes. 2010;5:265-73. doi: 10.3109 /17477160903268282.

10. Sweeting HN. Gendered dimensions of obesity in childhood and adolescence. Nutr J. 2008;7:1. doi: 10.1186/1475-2891 $-7-1$.

11. Phipps SA, Burton PS, Osberg LS, Lethbridge LN. Poverty and the extent of child obesity in Canada, Norway and the United States. Obes Rev. 2006;7(1):5-12. doi: 10.1111/j.1467-789X.2006.00217.x.

12. Ogden CL, Carroll MD, Kit BK, Flegal KM1. Prevalence of childhood and adult obesity in the United States, 2011-2012. JAMA. 2014;311(8):806-14. doi: 10.1001 /jama.2014.732.
13. Public Health England. Child weight data factsheet. London (UK): Public Health England; 2015 Oct. Report no. 2015432.

\section{OPEN CALL SU B (1) CA Canada

In 2015, we published articles with authors from almost all provinces and territories.

We welcome submissions of manuscripts with practical, authoritative information on infectious diseases that will inform policy, program and practice.

Visit: www.phac-aspc.gc.ca/publicat/ccdr-rmtc/ia-ra-eng.php 